Article

\title{
DFO@EVOH and 3,4-HP@EVOH: Towards New Polymeric Sorbents for Iron(III)
}

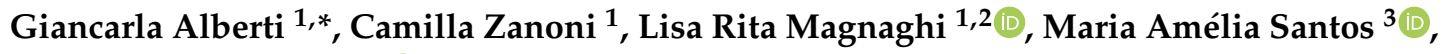 \\ Valeria Marina Nurchi ${ }^{4}\left(\mathbb{D}\right.$ and Raffaela Biesuz ${ }^{1,2}$ \\ 1 Dipartimento di Chimica, Università di Pavia, Viale Taramelli 12, 27100 Pavia, Italy; \\ camilla.zanoni01@universitadipavia.it (C.Z.); lisarita.magnaghi01@universitadipavia.it (L.R.M.); \\ rbiesuz@unipv.it (R.B.) \\ 2 Unità di Ricerca di Pavia, INSTM, Via G. Giusti 9, 50121 Firenze, Italy \\ 3 Centro de Química Estrutural, Istituto Superior Tecnico, Universidade de Lisboa, Av. Rovisco Pais 1, \\ 1059-001 Lisboa, Portugal; masantos@tecnico.ulisboa.pt \\ 4 Dipartimento di Scienze della Vita e dell'Ambiente, Università di Cagliari, Cittadella Universitaria, \\ 09042 Monserrato-Cagliari, Italy; nurchi@unica.it \\ * Correspondence: galberti@unipv.it
}

Received: 25 September 2020; Accepted: 3 November 2020; Published: 5 November 2020

\begin{abstract}
The paper presents the synthesis and preliminary characterization of two novel solid-phase sorbents for iron(III), resulting from the functionalization of ethylene-vinyl alcohol copolymer (EVOH) with deferoxamine, DFO (DFO@EVOH), and a novel tripodal 3-hydroxy-4-pyridinone, named 3,4-HP (3,4-HP@EVOH). DFO and 3,4-HP have been covalently bonded to EVOH, using carbonyldiimidazole as a coupling agent. Before their use as Fe(III) sorbents, they were warm-pressed to obtain a thin film. Polymers have been characterized by conventional physico-chemical techniques; furthermore, the sorption properties towards Fe(III) were investigated. The physico-chemical characterization of the new solid-state devices demonstrates the effective linkage of the two receptors on the polymeric support. Despite a relatively low sorption capacity for both materials, the stoichiometry and the complexation constants of $\mathrm{Fe}(\mathrm{III}) / \mathrm{DFO} @ \mathrm{EVOH}$ and $\mathrm{Fe}(\mathrm{III}) / 3,4-\mathrm{HP} @ \mathrm{EVOH}$ are in pretty good agreement with those obtained for the same ligands in aqueous solutions.
\end{abstract}

Keywords: iron(III) sorbents; functionalized polymers; ethylene-vinyl alcohol; deferoxamine; tris 3-hydroxy-4-pyridinone

\section{Introduction}

Iron is the fourth most abundant element in the Earth's crust, with an abundance of $5 \sim 6 \%$. The low Fe concentration in water is due to its poor solubility, ranging from $10^{-6} \mathrm{M}$ in river water to $10^{-6}$ to $10^{-9} \mathrm{M}$ in coastal water and about $10^{-11} \mathrm{M}$ in ocean water. The concentration of $\mathrm{Fe}$ in the open oceans influences $\mathrm{CO}_{2}$ content in the atmosphere and, hence, global climate, with Fe concentrations in the ocean supplied from surrounding land and sediments [1].

Iron is a metal essential for life, involved in many strategic metabolic pathways, such as in the oxygen transport system and the electron transfer chain (respiration). Fe(III) is moderately toxic compared to other transition metal ions but it is classified as an environmental pollutant at high concentrations; indeed, excessive iron(III) provokes several health problems [2].

Moreover, the presence of Fe(III) in biological systems has to be efficiently moderated since both its deficiency and overloading can induce several biological disorders [3]. One of the most severe effects of iron overload is the capacity of the $\mathrm{Fe}(\mathrm{II}) / \mathrm{Fe}(\mathrm{III})$ redox cycle to produce dangerous hydroxyl free radicals; on the contrary, low iron(III) levels reduce its concentration in the hemoglobin and generate 
pathologies such as thrombocytosis or hypoxia [4]. Iron-chelation therapy is commonly used in people affected by iron overload to maintain a correct Fe(III) level in the organism [5], but the long-term use of iron(III) chelators can lead to severe side effects [6,7].

Given these issues, it should be necessary to develop highly selective materials for iron(III) [2,8-11].

It has been demonstrated that, through the resin titration technique [12-14], it is possible, not only the pre-concentration and separation of a target analyte but also obtaining information about metal ion speciation and an evaluation of the free fraction. The information about the distribution of metal ion species in the original sample can be obtained from the competition between the natural ligand in the sample and the resin using a particular ratio quantity of resin/volume of the sample. Increasing the strength of the ligand and reducing the resin amount, the sorbed metal fraction decreases. When the capability of the resin to bind the metal ion is known, it was demonstrated that it is possible to determine the collateral reaction coefficient [15], $\alpha_{M}=c_{M} /[M]$, and if the total content $\left(c_{M}\right)$ is also known, the free metal ion concentration, $[\mathrm{M}]$ can also be achieved.

According to this strategy, it is possible to develop different solid materials (passive sampler, specific functionalized materials, and biopolymers) to assess the free iron(III) concentration in a very complex matrix. Nevertheless, to have a selective sorbent for iron(III) determination, commercial resins are not helpful since they are active to a large class of compounds [16]. For this reason, a new strategy was followed in our group, and in particular, for iron(III), we already developed probes based on deferoxamine (DFO) as a receptor and using silica and filter paper as solid supports $[17,18]$. These devices are suitable sorbents of $\mathrm{Fe}(\mathrm{III})$ but they are fragile since they can decompose in alkaline media; besides, silica is not easy to handle for Solid Phase Extraction (SPE) applications.

In the present research, we explore the possible use of ethylene-vinyl alcohol copolymer, EVOH, as a support to obtain an extrudable material, which, in principle, is much more convenient for a practical application thanks to its ability to be dissolved in hydro-alcoholic mixtures and applied by coating or printing procedures on flexible substrates [19-23].

We functionalized it with deferoxamine, DFO, and a new tripodal 3-hydroxy-4-pyridinone, 3,4-HP, which has been recently reported as a strong iron(III)-sequestering agent [24] (see Figure 1).

(A)<smiles>CC(=O)N(O)CCCCCNC(=O)CCC(=O)N(O)CCCCCNC(=O)CCC(=O)N(O)CCCCCN</smiles>

(B)

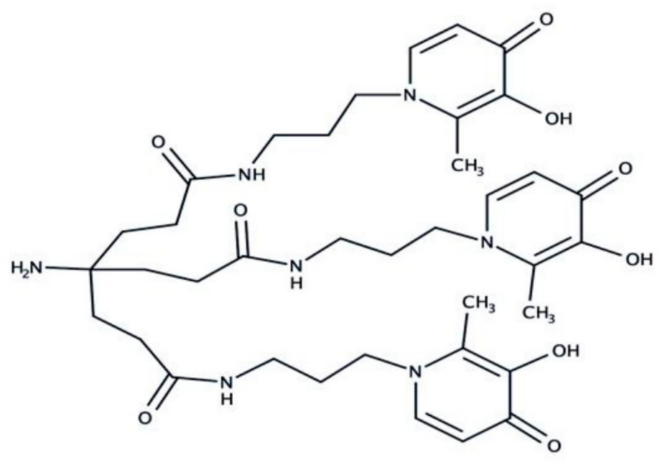

Figure 1. Structure formulae of (A): deferoxamine (DFO) and (B): tris 3-hydroxy-4-pyridinone (3,4-HP).

Conventional physico-chemical methods are used to characterize both functionalized materials. The isotherm profiles and the complexing properties towards Fe(III) of the new solid polymers are presented and discussed. 


\section{Experimental}

\subsection{Materials}

\subsubsection{Chemicals}

All chemicals were of analytical grade.

EVOH 32\% was obtained fromIndustria Termoplastica Pavese (ITP) (Bosnasco, PV, Italy); the percentage refers to the co-monomer composition. Carbonyldiimidazole, dimethyl sulfoxide (DMSO, anhydrous), EDTA (disodium salt), $\mathrm{KNO}_{3}, \mathrm{HNO}_{3}, \mathrm{HCl}$, and $\mathrm{NaOH}$ were purchased from Sigma-Aldrich, Italy.

Deferoxamine mesylate salt (DFO, Desferal-NOVARTIS FARMA SpA) was bought in a local pharmacy. The tris 3-hydroxy-4-pyridinone, 3,4-HP, was synthesized by M.A. Santos' group at the "Centro de Química Estrutural, Istituto Superior Tecnico, Universidade de Lisboa"; Ref. [24] reports the details of this synthesis.

All of these reagents were used as received.

Iron $1000 \mathrm{mg} \cdot \mathrm{L}^{-1}$ (Fluka) ICP standard was used to prepare the $\mathrm{Fe}(\mathrm{III})$ solutions at a proper concentration. All aqueous solutions were prepared with ultrapure water.

\subsubsection{Instruments}

For elemental analysis, NMR spectroscopy, SEM/EDS, FTIR, ICP-MS, facilities at the University of Pavia (Chemistry Department, Physics Department, and the instrument service center "Centro Grandi Strumenti, CGS") were used.

IR analyses were obtained with an FTIR Nicolet (iS10, Nicolet, Waltham, MA, USA). Scanning electron microscopy (SEM) measurements and energy-dispersive X-ray spectroscopy (EDX) microanalysis were performed using a Zeiss EVO MA10 (Carl Zeiss, Oberkochen, Germany) coupled with an EDS detector (X-max $50 \mathrm{~mm}^{2}$, Oxford Instruments, Oxford, UK) calibrated with a cobalt standard on samples deposited on a $\mathrm{C}$ bi-adhesive layer. Thermal analysis was performed by a differential scanning calorimeter (DSC), Q2000 V14, TA Instruments. Additionally, 1NMR spectra were registered with a Bruker AVANCE $200 \mathrm{MHz}$ instrument.

The solution $\mathrm{pH}$ was measured by an Orion $420 \mathrm{pH}$ meter with a combined glass electrode (Mettler Toledo, Milano, Italy), standardized in $\mathrm{H}^{+}$concentration; the equilibrium criterionwas $0.1 \mathrm{mV} \mathrm{min}^{-1}$.

The concentration of Fe(III) in aqueous solutions was determined by ICP-MS (SCIEX ELAN 6000, Perkin Elmer, Milan, Italy), according to the instrument manufacturer's method.

\subsubsection{Synthesis}

The synthetic pathway adopted provides the use of carbonyldiimidazole (CDI) as a coupling agent $(\mathrm{Xu}, 2018)$ for the functionalization of the copolymer EVOH with DFO and 3,4-HP.

The synthesis consisted of two steps, as schematized in the following Figure 2.

Since EVOH is soluble in DMSO, all reactions were carried out in this solvent.

The first step was a coupling reaction between EVOH copolymer and CDI: the product was obtained by dissolving the reagents in DMSO for $3 \mathrm{~h}$ at room temperature and under Ar flow. The nucleophilic hydroxyl group of the copolymer attacks the electrophilic carbonyl of the carbonyldiimidazole. For the subsequent reaction, the product of the first step was contacted with $\mathrm{DFO} / \mathrm{Fe}(\mathrm{III})$ or $3.4-\mathrm{HP} / \mathrm{Fe}(\mathrm{III})$ complex (R1-NH $\mathrm{NH}_{2}$ in the scheme of Figure 2) in DMSO for $20 \mathrm{~h}$ at room temperature and under argon flow. It was essential to add the ligand as a complex with Fe(III), ensuring that only the terminal amino group might be involved in the covalent bond with the solid mainframe.

At the end of the reaction, the polymer was precipitated with about $150 \mathrm{~mL}$ of cold $\mathrm{CH}_{2} \mathrm{Cl}_{2}$. The suspension was filtered on a buchner and dried in a vacuum dryer.

The final polymeric solids, DFO@EVOH and 3,4-HP@EVOH, were red/brown- and purple-colored, respectively. 


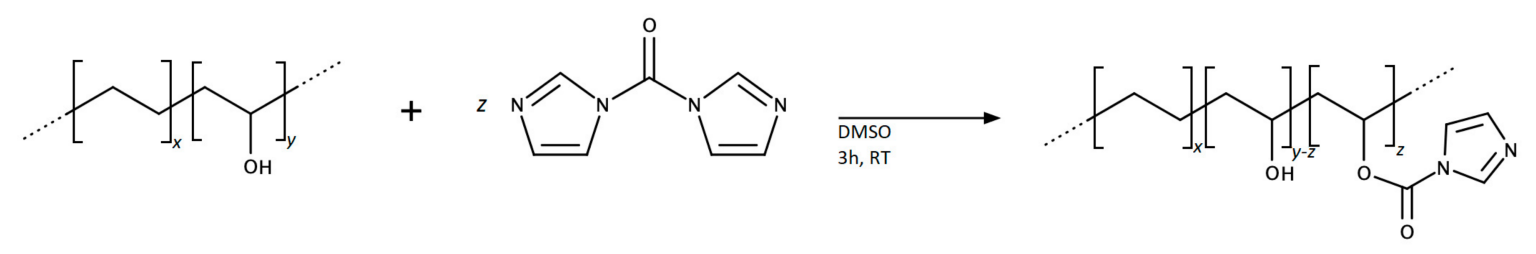

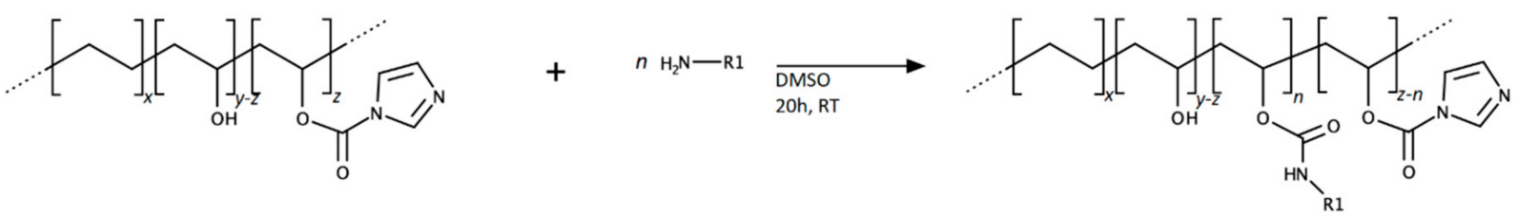

Figure 2. Scheme of the synthetic pathway for the preparation of the random copolymer DFO@ ethylene-vinyl alcohol copolymer $(\mathrm{EVOH})$ or 3,4-HP@EVOH. R1- $\mathrm{NH}_{2}$ can be a DFO/Fe(III) or 3,4-HO/Fe(III) complex. EVOH 32\%: $0.50 \mathrm{~g}$; DMSO: $10 \mathrm{~mL}$; carbonyldiimidazole (CDI): $0.70 \mathrm{~g}$; DFOm/3,4-HO: $0.10 \mathrm{~g} ; \mathrm{Fe}\left(\mathrm{NO}_{3}\right)_{3}: 0.04 \mathrm{~g}$.

For the subsequent analytical applications, DFO@EVOH and 3,4-HP@EVOH had to be extruded until thin films were obtained. So, they were warm-pressed at $140{ }^{\circ} \mathrm{C}$ for 20 min and then further pressed at 2000 psi for $30 \mathrm{~s}$ to obtain a film of $50-\mu \mathrm{m}$ thickness.

After pressing, the polymers' sheets were cut in small clips by a hole punch for papers; the average weight of each of them was around $3.5 \mathrm{mg}$.

Afterward, for the removal of Fe(III), the procedure applied was different for each polymer. The DFO-EVOH was treated with portions of an EDTA $0.1 \mathrm{M}$ solution, overnight, under mild stirring on a shaking plate-this procedure was repeated until the complete leaking of Fe(III) from the polymer, i.e., when the concentration of Fe(III) in the EDTA solution was lower than the limit of detection (LOD) of the method (ICP-MS). Otherwise, due to the very low speed of Fe(III) desorption with EDTA, the 3,4-HP@EVOH was contacted with portions of HF $1 \mathrm{M}$ solution for $5 \mathrm{~min}$, following the same procedure described for DFO@EVOH.

\subsubsection{Isotherm Experiments}

Sorption isotherms were performed by discontinuous procedures. Circular clips of 0.5 -cm diameter (of about $3.5 \mathrm{mg}$ ) of each solid phase were put in contact overnight at room temperature, with $0.5 \mathrm{~mL}$ of $0.1 \mathrm{M} \mathrm{HCl}$ solutions for DFO@EVOH and 0.01 M HCl solutions for 3,4-HP@EVOH at different Fe(III) concentration (from 0 to $0.75 \mathrm{mM}$ ) and gently stirred on a shaking plate. When the equilibrium was reached, a small amount of solution was collected, diluted with $0.5 \% \mathrm{HNO}_{3}(v / v)$ in disposable testing tubes, and analyzed by ICP-MS to determine the iron(III) remaining in the solution. The amount of sorbed iron(III) was determined by subtraction from the total metal ion content.

\subsubsection{Desorption Experiments}

For these experiments, a discontinuous procedure was applied. Different circular clips of 0.5-cm diameter of each DFO@EVOH or 3,4-HP@EVOH polymer were put in contact with an appropriate amount of $\mathrm{Fe}(\mathrm{III})$ at $\mathrm{pH}$ around 2 until saturation of the active sites of the polymer.

After equilibration, the solution was removed and each clip of the solid phase was repetitively washed with ultrapure water. The Fe(III)-DFO@EVOH or Fe(III)-3,4-HP@EVOH so obtained was equilibrated with solutions of 1,4-piperazinediethanesulfonic acid (PIPES) buffer $0.1 \mathrm{M}$ at $\mathrm{pH}$ about 7, containing different concentrations of DFO as a competitive ligand. After equilibration, a small amount of each solution was collected in a disposable testing tube and analyzed by ICP-MS for dosing iron(III) content. The desorption profiles were obtained by plotting the fraction of sorbed metal ion, $f$, vs. competitive ligand concentration. 


\section{Results and Discussion}

\subsection{Physico-Chemical Characterization}

Comparison between the FTIR spectra of DFO and 3,4-HP and the relative polymers DFO-EVOH and 3,4-HP-EVOH clearly shows the actual functionalization of the solid matrix EVOH due to the appearance of a peak at $1707 \mathrm{~cm}^{-1}$ for DFO@EVOH and at $1727 \mathrm{~cm}^{-1}$ for 3,4-HP@EVOH, attributable to the carbamate group (-O-CO-NHR1, see Figure 2). Figure 3 illustrates the FTIR spectra of DFO@EVOH and 3,4-HP@EVOH.

The significant chemical shifts of 1H-NMR spectra and FTIR frequency peaks are reported as described below for the characterization of the new chelating matrices.

DFO. IR: $v_{\max }\left(\mathrm{cm}^{-1}\right)$ : 3304, $3095(\mathrm{NH}) ; 2927,2855(\mathrm{CH}) ; 1618(\mathrm{~N}-\mathrm{C}=\mathrm{O})$.

${ }^{1} \mathrm{H}-\mathrm{NMR}\left(\mathrm{DMSO}, 25{ }^{\circ} \mathrm{C}, 200 \mathrm{MHz}\right) \delta: 1.33-1.45 ; 2.22 ; 2.49 ; 2.56 ; 2.7 ; 2.75 ; 3.03 ; 3.46$.

DFO@EVOH. IR: $v_{\max }\left(\mathrm{cm}^{-1}\right): 3354\left(\mathrm{OH}_{\mathrm{pol}}\right) ; 2929,2854(\mathrm{CH}) ; 1707(\mathrm{O}-\mathrm{CO}-\mathrm{N}) ; 1647(\mathrm{~N}-\mathrm{C}=\mathrm{O})$. ${ }^{1} \mathrm{H}-\mathrm{NMR}$ (DMSO, $\left.25^{\circ} \mathrm{C}, 200 \mathrm{MHz}\right): 0.69^{\prime} 1.22$ (C-H, O-H pol).; 3.56; 3.73; 4.16; 4.44.

3,4-HP. IR: $v_{\max }\left(\mathrm{cm}^{-1}\right)$ : 3247, $3070(\mathrm{NH}) ; 2932(\mathrm{CH}) ; 1622(\mathrm{~N}-\mathrm{C}=\mathrm{O}) ; 1230(\mathrm{C}-\mathrm{O})$.

${ }^{1} \mathrm{H}-\mathrm{NMR}$ is described in reference (Kim, 2014) in deuterated methanol: ${ }^{1} \mathrm{H}$ NMR $(400 \mathrm{MHz}$, MeOD-d4), $\delta$ (ppm): 7.65 (d, 2H, $\left.J=8.0 \mathrm{~Hz}, \mathrm{PyH}-6^{\prime \prime}\right), 6.40\left(\mathrm{~d}, 2 \mathrm{H}, J=8.0 \mathrm{~Hz}, \mathrm{PyH}-6^{\prime \prime}\right), 4.10(\mathrm{t}, 4 \mathrm{H}$, $\left.J=8.0 \mathrm{~Hz}, \mathrm{H}-3^{\prime}\right), 3.28\left(\mathrm{t}, 4 \mathrm{H}, J=8.0 \mathrm{~Hz}, \mathrm{H}-1^{\prime}\right), 2.45$ (s, 9H, $\left.\mathrm{CH}_{3} \mathrm{Py}\right), 2.31-2.37$ (m, 4H, H-6), 2.23'2.28 (m, $4 \mathrm{H}, \mathrm{H}-2), 1.90-1.99$ (m, 10H, H-3, H-5 \& H-2').

3,4-HP@EVOH. IR: $v_{\max }\left(\mathrm{cm}^{-1}\right): 3374\left(\mathrm{OH}_{\mathrm{pol}}\right) ; 2927,2855(\mathrm{CH}) ; 1727\left(\mathrm{O}^{\prime} \mathrm{CO}^{\prime}-\mathrm{N}\right) ; 1655\left(\mathrm{~N}^{\prime} \mathrm{C}=\mathrm{O}\right)$.

SEM images allow us to observe the formation of microcrystals and nanocrystals on the surface of the solid. The presence of iron(III) in both polymers is evident by the naked eye because of the change in the materials' colors: DFO@EVOH turns red/brown and 3,4-HP@EVOH becomes purple.

Unfortunately, the EDX spectra of both polymers loaded with Fe(III) were not very useful due to the contamination with several ubiquitous elements $(\mathrm{C}, \mathrm{Al}, \mathrm{Si}$, and $\mathrm{Mg}$ ), which prevented the quantitative determination of iron(III). However, the EDX analysis, together with the color change, ensured the formation of the complex with Fe(III). The quantity of Fe(III) loaded was then determined by isotherm experiments.

DSC measurements of the DFO@EVOH and 3,4-HP@EVOH polymers were carried out to observe the polymers' possible melting point changes after functionalization.

For EVOH, according to reported literature [25-27], all the works are entirely in agreement on a polymer melting temperature of about $180^{\circ} \mathrm{C}$, and variations of $\pm 10^{\circ} \mathrm{C}$ are attributable to the different degrees of humidity and the different percentages of ethylene.

In the thermogram of the DFO@EVOH polymer, we observed a peak that falls at $\mathrm{T}_{\mathrm{m}}=170.16{ }^{\circ} \mathrm{C}$; this temperature agreed with evidence from experiments during the hot-pressing of the polymer.

Some instrumental problems did not allow us to perform a good DSC analysis for 3,4-HP@EVOH, so for this preliminary polymer, we decide to keep an experimentally obtained temperature of $160^{\circ} \mathrm{C}$ for the hot-pressing of the material.

Figure 4 shows the SEM images for DFO@EVOH and 3,4-HP@EVOH, both loaded with Fe(III). 


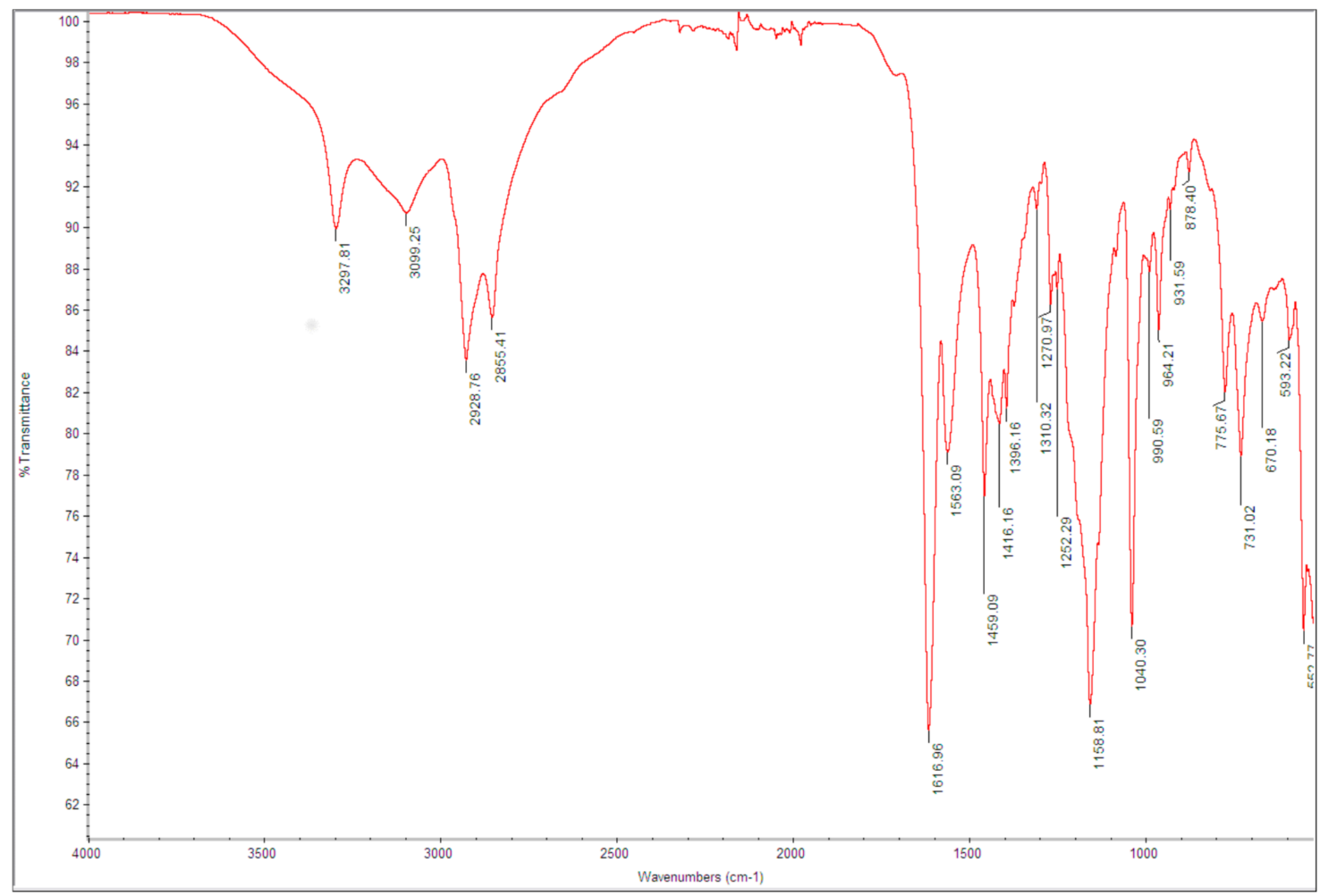

(a)

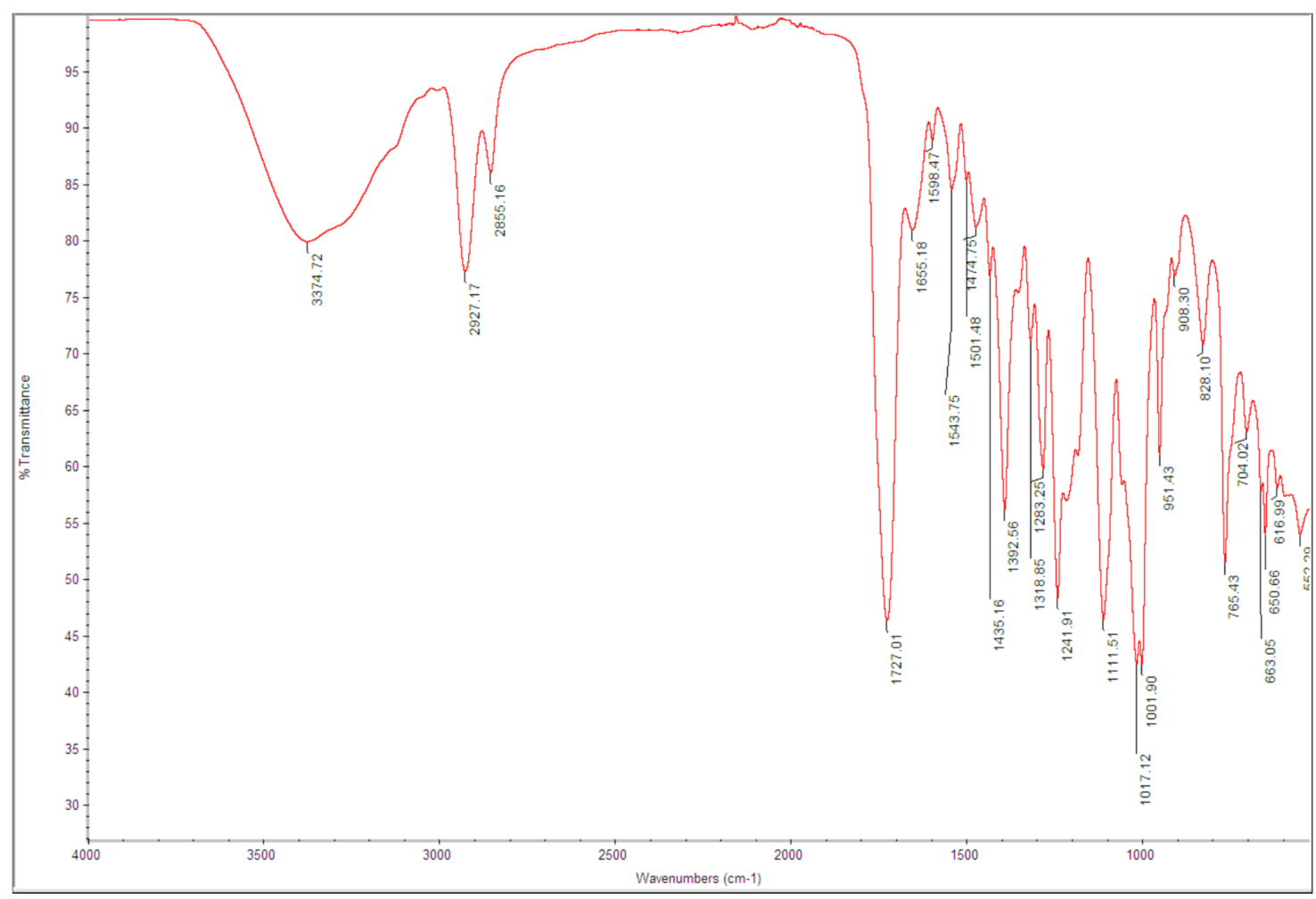

(b)

Figure 3. FTIR spectra in the solid phase of (a) DFO@EVOH and (b) 3,4-HP@EVOH. 


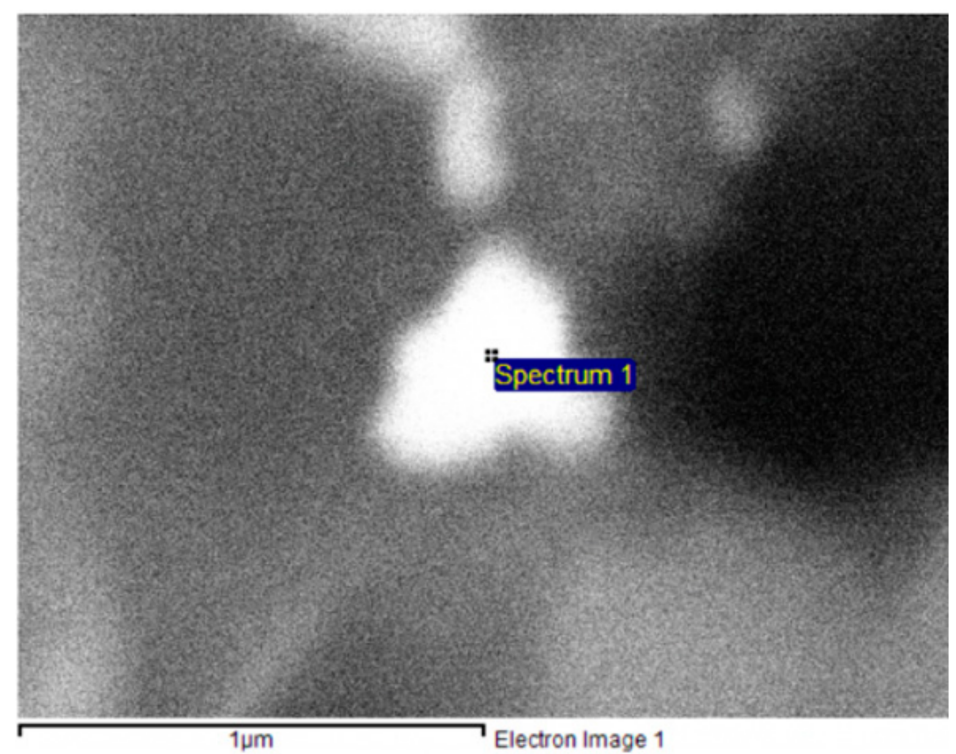

(A)

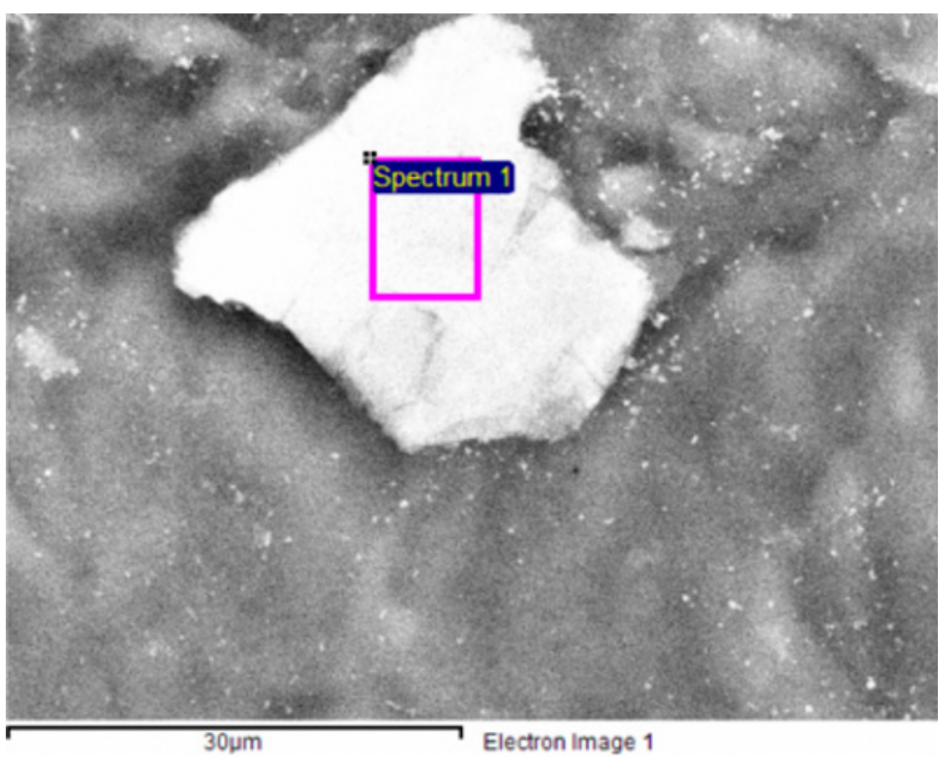

(B)

Figure 4. SEM images for (A) Fe(III)-DFO@EVOH and (B) Fe(III)-3,4-HP@EVOH.

\subsection{Sorption Isotherms}

In solid sorbent development, an important parameter to evaluate is the maximum sorption capacity $\left(q_{\max }, \mathrm{mmol} \cdot \mathrm{g}^{-1}\right)$, representing the number of active sites available under defined conditions for metal ion sorption.

Often used are the Langmuir and the Freundlich models, suitable to describe the relationships between the sorbed quantity, $q\left(\mathrm{mmol} \cdot \mathrm{g}^{-1}\right)$, and the analyte concentration in solution when the equilibrium has been reached $C_{\text {eq }}(\mathrm{M})$. Many reviews report their different characteristics (see, for instance, [28]), so they will not be further commented on here.

We know that it is essential to know the total amount of ligand fixed on the polymers, but for this preliminary screening, we decided to evaluate only the amount of ligand interested in the Fe(III) complexation, i.e., the maximum sorption capacity. 
Figure 5 reports the sorption isotherms of both DFO@EVOH and 3,4-HP@EVOH, obtained at $25^{\circ} \mathrm{C}$ in $0.1 \mathrm{M} \mathrm{HCl}$ for DFO@EVOH and in $0.01 \mathrm{M} \mathrm{HCl}$ for 3,4-HP@EVOH. The continuous lines are the best fitting obtained by applying the Langmuir equation.

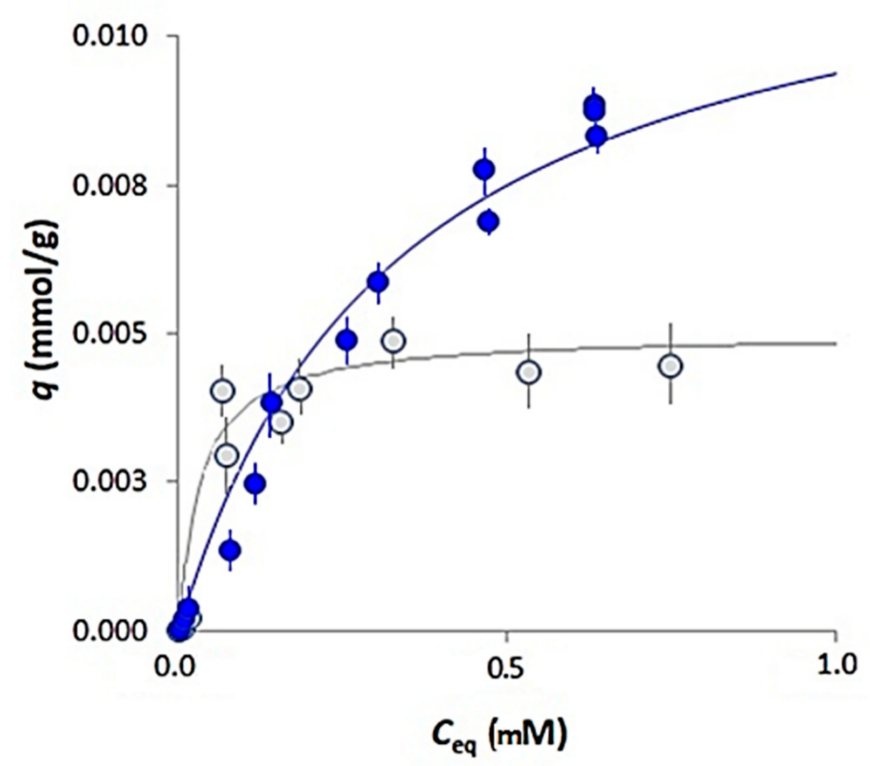

Figure 5. Sorption isotherms for the system Fe(III)/DFO@EVOH (grey circles; $\mathrm{T}=25^{\circ} \mathrm{C}$, circular clips of $3.5 \mathrm{mg}$ contacted with $0.5 \mathrm{~mL}$ of $0.1 \mathrm{M} \mathrm{HCl}$ at different $\mathrm{Fe}(\mathrm{III})$ concentration-from 0 to $0.75 \mathrm{mM}$ ) and for the system $\mathrm{Fe}(\mathrm{III}) / 3,4-\mathrm{HP} @ \mathrm{EVOH}$ (blue circles; $\mathrm{T}=25^{\circ} \mathrm{C}$, circular clips of $3.5 \mathrm{mg}$ contacted with $0.5 \mathrm{~mL}$ of $0.01 \mathrm{M} \mathrm{HCl}$ at different $\mathrm{Fe}(\mathrm{III})$ concentration-from 0 to $0.75 \mathrm{mM}$ ). Continuous lines are the best fitting lines by the Langmuir equation. Error bars represent the standard deviation on three replicates.

The different choice in the solution $\mathrm{pH}$ is due to the two ligands' different complexation behaviors toward Fe(III). In any case, we worked with very acid media since in synthetic solutions at $\mathrm{pH}$ higher than 3, Fe(III) hydrolysis occurs; moreover, it is well known from the literature (see, for example, [24,29]) that both DFO and 3,4-HP form stable complexes also in such acid media.

The $q_{\max }$ values obtained from these experiments are $0.005(1) \mathrm{mmol} \cdot \mathrm{g}^{-1}$ for the system $\mathrm{Fe}(\mathrm{III}) / \mathrm{DFO} @ \mathrm{EVOH}$ and 0.013(2) $\mathrm{mmol} \cdot \mathrm{g}^{-1}$ for the system Fe(III)/3,4-HP@EVOH.

Both polymers have a relatively low maximum sorption capacity, at least one order of magnitude lower than that of commercial sorbents and natural polymers. This experimental evidence can be interpreted considering that the metal ion does not permeate within the polymer but remains only on the surface, i.e., only the active binding sites present on the polymer's surface can coordinate the cation.

Although the low maximum sorption capacity does not allow the use of these materials as colorimetric sensors, their high selectivity and ability to complex Fe(III), even at such low $\mathrm{pH}$, allows their application as sorbents for trace analysis, also in very acid solutions.

\subsection{Desorption Profiles}

Desorption experiments aim to verify the complexing properties of the functionalized polymers DFO@EVOH and 3,4-HP@EVOH towards Fe(III).

We followed a strategy already applied for chelating resins [12-14,28,30,31], which enables the interpretation of the sorption reactions and the computation of the corresponding exchange constants.

For both polymers, it was assumed, to a first approximation, that the protonation constants of the DFO and 3,4-HP, covalently bound to the EVOH mainframe, were the same as both ligands in an aqueous solution (obviously removing the protonation constants of the free amine that is now involved in the linkage with the $\mathrm{EVOH}$ mainframe). As also verified for some similar 
materials, this assumption becomes valid upon determining the complexation constants: if the sorption mechanisms, the stoichiometry of the complexes, and their constants agree with those in solution, the protonation constants can be considered the same as the free ligands in aqueous solution.

DFO and 3,4-HP can sorb Fe(III) even at acid pH, lower than 2. Since we aim to apply these polymers as sensors of $\mathrm{Fe}(\mathrm{IIII})$ also in biological fluids, the characterization has to be extended at neutral $\mathrm{pH}$. Consequently, we decided to explore the sorption mechanism by performing desorption experiments in the presence of a competitive ligand. This strategy is indispensable to avoid Fe(III) hydrolysis at a $\mathrm{pH}$ closer to that expected for the real samples [14].

For these experiments, each solid phase was left to equilibrate with $\mathrm{Fe}(\mathrm{III})$ at acidic $\mathrm{pH}$ until saturation of the active sites. The solution was removed, and after 3-4 washes with ultrapure water, the Fe(III)-DFO@EVOH and the Fe(III)-3,4-HP@EVOH obtained were put in contact with solutions at $\mathrm{pH}$ 7.0, using PIPES as a buffer and containing increasing concentrations of DFO as a competitive ligand. In this way, iron(III) was desorbed, step by step, by increasing the concentration of DFO from 0 to a quantity sufficient to allow the complete removal of Fe(III). Figures 6 and 7 show, for each polymer, the desorption plot obtained reporting the fraction of sorbed metal ion, $f$, vs. the competitive ligand concentration.

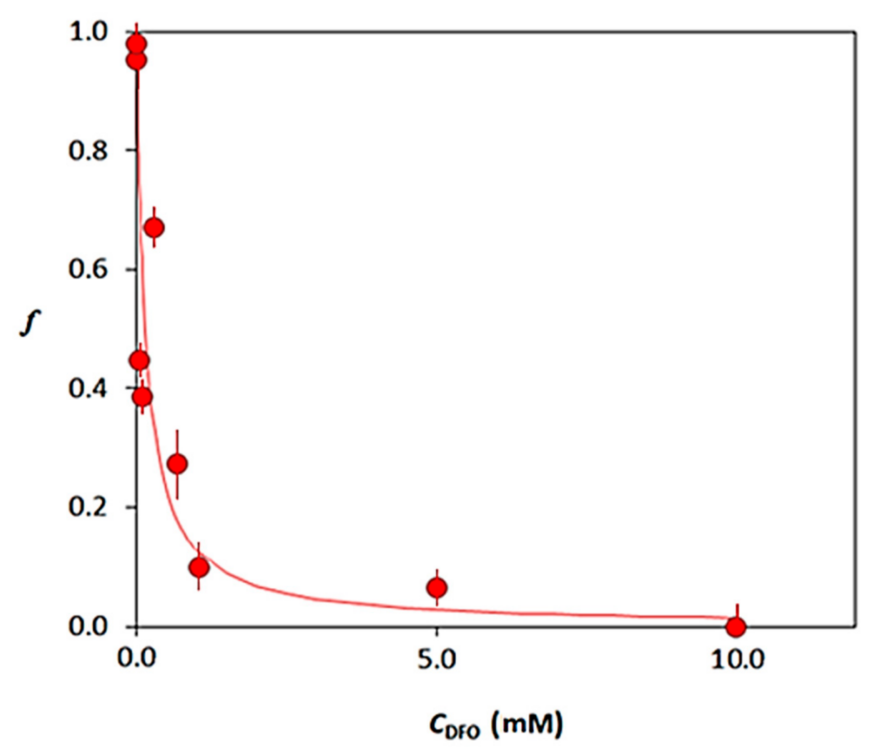

Figure 6. Desorption profile of Fe(III) from Fe(III)-DFO@EVOH, at pH 7, as a function of the DFO concentration added in solution. Discontinuous procedure. Solid phase: Fe(III)-enriched DFO@EVOH (circular clips $3.5 \mathrm{mg}$ ); solution phase: PIPES buffer $0.1 \mathrm{M}$ at $\mathrm{pH} 7, V=1.5 \mathrm{~mL}$. Error bars represent the standard deviation on three replicates.

In Figures 6 and 7, the continuous curves are calculated by the following Equation (1):

$$
f=\frac{c}{c_{\text {tot }}}=\frac{1}{1+\frac{\alpha_{\mathrm{M}} \cdot \alpha_{\mathrm{L}} \cdot V}{\beta_{\mathrm{ex}} \cdot\left[\mathrm{H}^{+}\right] \cdot c_{\mathrm{L}} \cdot w}}
$$

where $c$ and $c_{\text {tot }}$ are the concentration of the sorbed and the total metal ion, respectively; $V$ is the volume of the solution; $w$ is the mass of the dry solid phase.

$\alpha_{\mathrm{M}}$ is the collateral reaction coefficient of the metal [15]:

$$
\alpha_{\mathrm{M}}=\frac{c_{\mathrm{tot}}}{\left[\mathrm{Fe}^{3+}\right]}
$$


$c_{\mathrm{L}}$ represents the total amount of active sites (DFO or 3,4-HP) in the solid phase involved in $\mathrm{Fe}(\mathrm{III})$ complexation $(\mathrm{mmol} / \mathrm{g})$ and $\alpha_{\mathrm{L}}$ is the ratio between the total ligand and its free concentration:

$$
\alpha_{\mathrm{L}}=\frac{c_{\mathrm{L}}}{[\overline{\mathrm{L}}]}
$$

$\alpha_{\mathrm{M}}$ values are computed from the hydrolysis constants of $\mathrm{Fe}(\mathrm{III})$ and complexation constants of Fe-DFO in solution; we refer to the thermodynamic data for the complexes Fe(III)/DFO present in the literature [29]. The MEDUSA program [32] was applied to calculate $\alpha_{\mathrm{M}}$ at the ionic strength and the $\mathrm{pH}$ of interest.

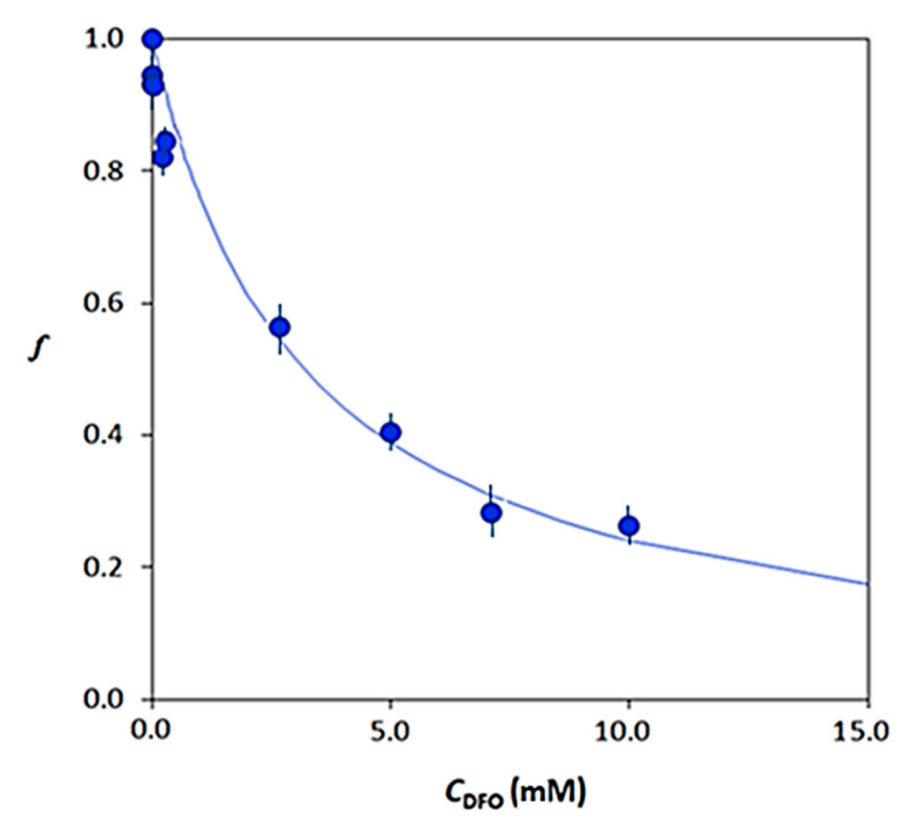

Figure 7. Desorption profile of Fe(III) from Fe(III)-3,4-HP@EVOH, at pH 7, as a function of the DFO concentration added in solution. Discontinuous procedure. Solid phase: Fe(III) enriched 3,4-HP@EVOH (circular clips $3.5 \mathrm{mg}$ ); solution phase: PIPES buffer $0.1 \mathrm{M}$ at $\mathrm{pH} 7, V=1.5 \mathrm{~mL}$. Error bars represent the standard deviation on three replicates.

$\beta_{\text {ex }}$ can be computed from Equation (1), knowing the stoichiometry of the complex formed in the solid phase at the $\mathrm{pH}$ of the experiment.

To compare the values of the complexation constants obtained in the solution phase, we have to consider the protonation of the free amine here linked to the solid mainframe. We named this re-calculated value $\beta_{\mathrm{ex}, \mathrm{corr}}$.

For the system Fe(III)/DFO@EVOH (see Figure 6), we have to consider that at $\mathrm{pH}$ around 7, the main complex is FeHDFO. The value obtained by Equation (1), considering the stoichiometry of this complex, is $\log \beta_{\mathrm{ex}}=31.4$ (2). The corresponding $\log \beta_{\mathrm{ex}, \mathrm{corr}}=42.1(2)$ is in quite good agreement with the value reported for the same complex in aqueous solution $\left(\log \beta_{\mathrm{FeHDFO}}=41.5\right.$ [29]).

The analogous procedure is followed for the system Fe(III)/3,4-HP@EVOH. We compared the stoichiometry and the constant with the value reported in [24]. Even then, the main species at $\mathrm{pH}$ around 7 was the complex $\mathrm{FeH}(3,4-\mathrm{HP})$ with a $\log \beta_{\mathrm{ex}, \mathrm{corr}}=45.2(1)$, not so different from the value obtained from the same complex in aqueous solution $\left(\log \beta_{\mathrm{FeH}}=45.77[24]\right)$.

\section{Conclusions}

The present work aims to synthesize polymers functionalized with selective ligands for Fe(III) to be used as sensors for analytical applications. 
Two strong Fe(III) chelating agents have been used: deferoxamine, a drug already on the market for many years for the treatment of pathologies involving the accumulation of $\mathrm{Fe}(\mathrm{III})$ in the body, here employed as a model molecule, as well as a recently developed tripodal binder, 3,4-HP, for the chelation of excess $\mathrm{Fe}(\mathrm{III})$.

The selected solid support for the sensors' preparation is EVOH 32\%, i.e., an ethylene vinyl alcohol copolymer in which $68 \%$ by moles is made up of repetitive units of vinyl alcohol.

The synthetic strategy used has made it possible to obtain products with the desired characteristics for the development of both sensors. The synthesis involves 1,1'-carbonyldiimidazole as a coupling agent. The polymers obtained both with DFO and with 3,4-HP are plastic and malleable; they can be pressed to obtain thin films without compromising the sorbent properties and they also provide an excellent response to the exchange of Fe(III) from aqueous solutions, with sorption and desorption processes that require reasonable times (about $24 \mathrm{~h}$ ).

The polymers were characterized in order to study their complexing properties towards Fe(III). Sorption isotherms and desorption profiles with a competing ligand have been set up. The results obtained demonstrate that both the polymers functionalized with DFO (DFO@EVOH) and with 3,4-HP $(3,4-\mathrm{HP} @ \mathrm{EVOH})$ can sorb Fe(III) at a very acidic $\mathrm{pH}(\mathrm{pH} 1 \div 2)$. The maximum sorption capacities $\left(q_{\max }\right)$ are not very high, being of the order of $0.01 \mathrm{mmol} / \mathrm{g}$; this result is presumably indicative of complexes forming between the active sites and the metal ions on the surface of the solid phase.

From desorption experiments, it was possible to obtain a preliminary estimate of the complexing constants of Fe(III) with the active sites of both polymers. The values achieved were compared with the constants of the analogs species studied in aqueous solution. The data obtained, although preliminary, are in good agreement with those reported in the literature, demonstrating that the synthetic strategy has not altered the chelating properties of the ligands anchored to the polymer and that the materials prepared can be effectively applied as sensors for Fe(III).

Author Contributions: Experiment and formal analysis, C.Z. and L.R.M.; writing-original draft preparation, G.A. and R.B.; writing-review and editing, V.M.N. and M.A.S. All authors have read and agreed to the published version of the manuscript.

Funding: This research received no external funding

Acknowledgments: We acknowledge Chiara Milanese (Hydrogen Lab, University of Pavia) for the IR, EDX, and SEM measurements; Karam Chand (Centro de Química Estrutural, Istituto Superior Tecnico, Universidade de Lisboa) for the synthesis of the 3,4-HP, funds provided from Fondi Ateneo Ricerca (FAR) of the University of Pavia, and MIUR for Lisa Rita Magnaghi's and Camilla Zanoni's grants. M. A. Santos is thankful to the Fundação para a Ciência e Tecnologia (FCT) for financial support to the project UID/QUI/00100/2019. We also thank the COST Action CA18202.

Conflicts of Interest: The authors declare no conflict of interest.

\section{References}

1. Zhu, Y.; Hu, X.; Pan, D.; Han, H.; Lin, M.; Lu, Y.; Wang, C.; Zhu, R. Speciation determination of iron and its spatial and seasonal distribution in coastal river. Sci. Rep. 2018, 8, 1-9. [CrossRef] [PubMed]

2. Oguz, M.; Kursunlu, A.N.; Yilmaz, M. Low-cost and environmentally sensitive fluorescent cellulose paper for naked-eye detection of Fe(III) in aqueous media. Dye. Pigment. 2020, 173, 107974. [CrossRef]

3. Abbaspour, N.; Hurrell, R.; Kelishadi, R. Review on iron and its importance for human health. J. Res. Med. Sci. 2014, 19, 164-174. [PubMed]

4. Halliwell, B.; Gutteridge, J.M.C. Free Radicals in Biology and Medicine, 2nd ed.; Clarendon Press: Oxford, UK, 2015.

5. Kalinowski, D.S.; Richardson, D.R. The Evolution of Iron Chelators for the Treatment of Iron Overload Disease and Cancer. Pharmacol. Rev. 2005, 57, 547-583. [CrossRef] [PubMed]

6. Crisponi, G.; Remelli, M. Iron chelating agents for the treatment of iron overload. Co-ord. Chem. Rev. 2008, 252, 1225-1240. [CrossRef]

7. Jones, G.; Goswami, S.K.; Kang, H.; Choi, H.S.; Kim, J. Combating iron overload: A case for deferoxamine-based nanochelators. Nanomedicine 2020, 15, 1341-1356. [CrossRef] 
8. Darmawan, W.; Nurani, D.A.; Rahayu, D.U.C.; Abdullah, I. Synthesis of Ion Imprinted Polymer for Separation and Preconcentration of Iron (III). In Proceedings of the 5th International Symposium on Current Progress in Mathematics and Sciences (Iscpms2019), Depok, Indonesia, 9-10 July 2019; Volume 2242, p. 040025. [CrossRef]

9. Eyyubova, E. Baku State University ADSORPTION STUDY OF Fe(III) IONS BY MASC-2-AMINO-4-NITROPHENOL. Azerbaijan Chem. J. 2020, 2, 26-33. [CrossRef]

10. Ahmad, K.; Hui, Y.Z.; Bairq, Z.A.S. Comparison of the performance of a hydrogel and hybrid graphene oxide with hydrogel to remove iron (III) and phenol from wastewater. Res. Chem. Intermed. 2020, 46, 2613-2639. [CrossRef]

11. Sui, D.-P.; Chen, H.-X.; Li, D.-W. Sol-gel-derived thiocyanato-functionalized silica gel sorbents for adsorption of Fe(III) ions from aqueous solution: Kinetics, isotherms and thermodynamics. J. SolGel. Sci. Technol. 2016, 80, 504-513. [CrossRef]

12. Biesuz, R.; Alberti, G.; D'Agostino, G.; Magi, E.; Pesavento, M. Determination of cadmium(II), copper(II), manganese(II) and nickel(II) species in Antarctic seawater with complexing resins. Mar. Chem. 2006, 101, 180-189. [CrossRef]

13. Pesavento, M.; Biesuz, R.; Gallorini, M.; Profumo, A. Sorption mechanism of trace amounts of divalent metal ions on a chelating resin containing iminodiacetate groups. Anal. Chem. 1993, 65, 2522-2527. [CrossRef]

14. Pesavento, M.; Biesuz, R.; Alberti, G.; Sturini, M. Characterization of the sorption of uranium(VI) on different complexing resins. Anal. Bioanal. Chem. 2003, 376, 1023-1029. [CrossRef]

15. Ringbom, A.; Still, E. The calculation and use of a coefficients. Anal. Chim. Acta 1972, 59, 143-146. [CrossRef]

16. Alberti, G.; Emma, G.; Colleoni, R.; Pesavento, M.; Nurchi, V.M.; Biesuz, R. Novel DFO-functionalized mesoporous silica for iron sensing. Part 2. Experimental detection of free iron concentration $(\mathrm{pFe})$ in urine samples. Anallyze 2014, 139, 3940-3948. [CrossRef]

17. Biesuz, R.; Emma, G.; Milanese, C.; Dacarro, G.; Taglietti, A.; Nurchi, V.M.; Alberti, G. Novel DFO-SAM on mesoporous silica for iron sensing. Part I. Synthesis optimization and characterization of the material. Analyze 2014, 139, 3932-3939. [CrossRef]

18. Alberti, G.; Quattrini, F.; Colleoni, R.; Nurchi, V.M.; Biesuz, R. Deferoxamine-paper for iron(III) and vanadium(V) sensing. Chem. Pap. 2015, 69, 1024-1032. [CrossRef]

19. Xu, D.; Lu, J.; Yan, S.; Xiao, R. Aminated EVOH nanofiber membranes for Cr(vi) adsorption from aqueous solution. RSC Adv. 2018, 8, 742-751. [CrossRef]

20. Salehi-Mobarakeh,H.; Yadegari, A.; Didehvar, J.; Khakzad-Esfahlan, F. Polyamide grafting onto ethylene-vinyl alcohol copolymer. J. Polym. Eng. 2013, 33, 843-850. [CrossRef]

21. Salgado, C.; Arrieta, M.P.; Chiloeches, A.; Muñoz-Bonilla, A.; Peponi, L.; López, D.; Fernández-García, M. Development of photoresponsive coumarin-modified ethylene-co-vinyl alcohol copolymers with antifouling behavior. React. Funct. Polym. 2020, 157, 104750. [CrossRef]

22. Du, J.; Dong, Z.; Yang, X.; Zhao, L. Facile fabrication of sodium styrene sulfonate-grafted ethylene-vinyl alcohol copolymer as adsorbent for ammonium removal from aqueous solution. Environ. Sci. Pollut. Res. 2018, 25, 27235-27244. [CrossRef]

23. Xie, K.; Dong, Z.; Wang, Y.; Qi, W.; Zhai, M.; Zhao, L. Facile Preparation of EVOH-Based Amphoteric Ion Exchange Membrane Using Radiation Grafting Technique: A Preliminary Investigation on Its Application for Vanadium Redox Flow Battery. Polymers 2019, 11, 843. [CrossRef]

24. Nurchi, V.M.; Cappai, R.; Chand, K.; Chaves, S.; Gano, L.; Crisponi, G.; Peana, M.; Zoroddu, M.A.; Santos, M.A. New strong extrafunctionalizable tris(3,4-HP) and bis(3,4-HP) metal sequestering agents: Synthesis, solution and in vivo metal chelation. Dalton Trans. 2019, 48, 16167-16183. [CrossRef]

25. Ossipov, D.A.; Hilborn, J. Poly(vinyl alcohol)-Based Hydrogels Formed by "Click Chemistry". Macromology 2006, 39, 1709-1718. [CrossRef]

26. Kim, D.; Kwon, H.; Seo, J. EVOH nanocomposite films with enhanced barrier properties under high humidity conditions. Polym. Compos. 2013, 35, 644-654. [CrossRef]

27. Sánchez-Chaves, M.; Ruiz, C.; Cerrada, M.; Fernández-García, M. Novel glycopolymers containing aminosaccharide pendant groups by chemical modification of ethylene-vinyl alcohol copolymers. Polymers 2008, 49, 2801-2807. [CrossRef]

28. Alberti, G.; Amendola, V.; Pesavento, M.; Biesuz, R. Beyond the synthesis of novel solid phases: Review on modelling of sorption phenomena. Co-ord. Chem. Rev. 2012, 256, 28-45. [CrossRef] 
29. Farkas, E.; Enyedy, É.A.; Csóka, H. A comparison between the chelating properties of some dihydroxamic acids, desferrioxamine B and acetohydroxamic acid. Polyhedron 1999, 18, 2391-2398. [CrossRef]

30. Alberti, G.; Biesuz, R.; Profumo, A.; Pesavento, M. Determination of the total concentration and speciation of $\mathrm{Al}(\mathrm{III})$ in tea infusions. J. Inorg. Biochem. 2003, 97, 79-88. [CrossRef]

31. Alberti, G.; Pesavento, M.; Biesuz, R. A chelating resin as a probe for the copper(II) distribution in grape wines. React. Funct. Polym. 2007, 67, 1083-1093. [CrossRef]

32. Puigdomenech, I. MEDUSA-Chemical Equilibrium Diagrams Program 32 Bit vers. Software for Windows; Royal Institute of Technology: Stockholm, Sweden, 2010.

Publisher's Note: MDPI stays neutral with regard to jurisdictional claims in published maps and institutional affiliations.

(C) 2020 by the authors. Licensee MDPI, Basel, Switzerland. This article is an open access article distributed under the terms and conditions of the Creative Commons Attribution (CC BY) license (http://creativecommons.org/licenses/by/4.0/). 